\title{
DIMENSIONS OF AUTOTELIC PERSONALITY AND THEIR EFFECTS ON PERCEIVED PLAYFULNESS IN THE CONTEXT OF MOBILE INFORMATION AND ENTERTAINMENT SERVICES
}

Felix B. Tan

Business Information Systems Department AUT University, New Zealand

Email: felix.tan@aut.ac.nz

\section{Jacky P.C. Chou}

School of Computing and Mathematical Sciences AUT University, New Zealand

Email: mr_lo8@hotmail.com

\begin{abstract}
Autotelic Personality represents an important individual construct in flow theory yet little is known about its underlying dimensions. Csikszentmihalyi (1988) suggested that the higher the autotelic nature of an individual, the more likely for him/her to experience flow. This study explores autotelic personality, its underlying dimensions and its relationship with perceived playfulness in the context of Mobile Information and Entertainment Services (MIES). This study found Autotelic Personality to be an important quality in order for users to experience perceived playfulness in the MIES context. Several underlying dimensions of Autotelic Personality were identified, including personal innovativeness, self efficacy and control.
\end{abstract}

\section{INTRODUCTION}

Autotelic Personality characterizes a person "who is able to enjoy what he is doing regardless of whether he will get external rewards from it and who thus is more likely to experience flow for a given activity" (Hoffman \& Novak, 1996). Flow represents an optimal experience when the challenges of a situation match the skills of the participant (Csikszentmihalyi, 1988). Flow is considered important in many technology settings including WWW, electronic library, e-Commerce as well as computer-mediated environments (Ghani, 1991; Hoffman and Novak, 1996; Koufaris, 2002).

In his study of happiness, Csikszentmihalyi (1988) identified what an 'autotelic' personality is - a person who sets their own goals, whether short-term or long-term, and then has great fun in achieving them. As Csikszentmihalyi stated:

"...the complexity of a flow activity is limited by the degree of challenge it can provide, and by the willingness and "creativity" of the person to create challenges in an activity. A person who can do this well, or who has the ability to enter a flow state relatively easy, is said to have an "autotelic personality"

Although Autotelic Personality was identified as an essential part of the Flow model by Csikszentmihalyi, very little research has explored its underlying dimensions (Finneran and Zhang, 2005; Nakamura and Csikszentmihalyi, 2002). This study treats and explores Autotelic Personality as a second-order construct reflected by four first-order factors: Personal Innovativeness; Self Efficacy; Control; and Focused Attention. 
The convergence of mobile commerce and internet technologies has promised users unprecedented convenience and greater enjoyment. In recent years, mobile information and entertainment services (MIES) have been gradually gaining popularity among mobile phone users (Garcia-Macias et al., 2003; Baldi and Thaung, 2002; Van de Kar et al., 2003). Research into mobile internet to date has by and large focused on extrinsic use of these services, for example, productivity and usefulness (Cheong and Park, 2005; Pedersen 2005; Wu \& Wang, 2005) and has largely ignored some important end-user characteristics. To better understand users' acceptance of MIES, we argue that it is equally important to examine an intrinsic motivator "Perceived Playfulness". Several studies have demonstrated the importance of this construct especially in the wider internet context (Chung and Tan, 2004; Lee et al., 2005), online retailing (Ahn et al., 2007), web portals (Lin et al., 2005) as well as mobile internet services (Nysveen et al., 2005; Fang et al., 2006). These studies agree that perceived playfulness is an important factor motivating users to use technologies like the internet, online retailing sites and mobile internet services - confirming when the individual's perception that attention is focused on the interaction, is curious during the interaction, and finds the interaction intrinsically enjoyable or interesting, the more likely the individual is to use that technology.

Perceived Playfulness was proposed by Moon and Kim (2001) based on the theory of flow (Csikszentmihalyi, 1988). Individuals experience flow when they are unconsciously engaged in an activity such that s/he becomes so engrossed thereby losing the sense of self (Chung and Tan 2004). These authors contend that playfulness occurs when individuals experience concentration, curiosity and enjoyment - concepts that are consistent with flow theory. However, some researchers have recently pointed out that individual differences have been ignored in many flow related studies (Finneran and Zhang, 2005; Nakamura and Csikszentmihalyi, 2002). Therefore to gain a better understanding of the role of Autotelic Personality in MIES, it is important to identify those individual differences likely to be related to Autotelic Personality and which contribute to the emergence of Perceived Playfulness. This study contributes to both research and practice. By focusing on the enduser characteristics, this work extends our understanding of the individual differences determining users' Perceived Playfulness as dimensions of one's Autotelic Personality in the context of users' intrinsic use of technology. In terms of practice, a clearer understanding of the individual differences in users' personalities has wide implications for market segmentation and providers of MIES should pay attention to the unique needs of different user groups.

\section{LITERATURE REVIEW AND RESEARCH MODEL}

Over the past few years, progress in mobile internet services has been remarkable, both in terms of technology and applications development (Shim and Shim, 2003). The introduction of real-time video-calling, Mobile TV, Multi Media Services and many other exciting offerings has seen the realization of faster mobile internet services through Third Generation Mobile Networking Technologies (3G). Mobile internet service is considered as one with high potential for its ability to carry out multiple services and to be truly convenient from a user's point of view. Among these services, mobile information and entertainment services (MIES) are gaining in popularity among mobile phone users (Garcia-Macias et al., 2003; Baldi and Thaung, 2002; Van de Kar et al. 2003). With increasing popularity, companies providing MIES will therefore benefit from sound conceptual and empirical research that enhance the understanding of the factors critical to user acceptance of MIES. We adopt van der Kar et al.'s (2003) definition of MIES as "the delivery of information and entertainment from specially formatted content sources (Internet sites, SMS, MMS, etc.) via the mobile telecommunication network to a mobile user" (p. 413). According to the authors, there are four basic functions mobile services provide - communication, transaction, information and entertainment. Unlike other types of mobile internet services, the focus of MIES is on the delivery of information and entertainment, made possible by recent developments in mobile telecommunications 
technology. Early MIES were based on Wireless Application Protocol (WAP). More recently, a variety of services including Short Message Service (SMS)-based information services and now Multimedia Message Service (MMS)-based information services are available.

As suggested earlier, research into mobile internet services to date tends to focus on the extrinsic use of these services and has largely ignored important intrinsic uses like Perceived Playfulness which is based on the Theory of Flow (Csikszentmihalyi, 1988).

\section{Flow Theory and Perceived Playfulness}

Flow represents an optimal experience when the challenges of a situation match the skills of the participant such that s/he becomes unconsciously engaged in the activity as though losing all sense of self (Csikszentmihalyi 1988). Flow experience can usually occur in structured activities such as games, ritual events, sports, artistic performances and etc. The flow theory assumes that the world is essentially in a state of chaos and that humans are intrinsically motivated to seek out those experiences that add order to consciousness to account for this chaos. Therefore, humans will tend to seek out those experiences with the most opportunity to achieve a flow experience. The theory assumes that it is within the ability of the subjective conscious to control, or provide order to, external stimuli. It claims that a flow state occurs when the challenges of a situation match the skills of the participant. If the challenges of a certain situation are above the participant's skills, then participants will perceive anxiety. Conversely, when the skills of the person are higher than that of the challenges of the situation, boredom will result. The importance of flow is recognized in various technology settings, such as personal computers, e-commerce, WWW, electronic library and Computer-Mediated Environment (CME) (Ghani, 1991; Koufaris, 2002; Hoffman and Novak, 1996; Trevino and Webster, 1992).

One of the most widely employed framework of IT/IS adoption is the Technology Acceptance Model (TAM) proposed by Davis (1989). TAM proposed two major determinants of user's intention toward IT/IS usage: Perceived Usefulness and Perceived Ease of Use. Their importance has been widely supported by many technology acceptance studies. However, one of the weaknesses of TAM lies in the fact that it is largely extrinsically focused. On the other hand, flow as an intrinsic motivator has attracted researchers' attention in IT/IS studies in recent years. One of the most phenomenal trends in personal computer usage during the last ten years has been the internet. A group of researchers have employed TAM to investigate user acceptance of internet-based technologies, such as email, virtual stores, online-shopping and general information searching websites (Trevino and Webster, 1992; Chen et al., 2002; Bhatnagar et al., 2000; Chung and Tan, 2004). These studies validated and extended the original model, providing a richer and more comprehensive picture of TAM to explain user acceptance of information systems.

Moon and Kim (2001) extended the TAM in the context of World Wide Web and found that Perceived Playfulness had a significant positive relationship with Attitude toward Using and Behavioral Intention. They also suggested people use the internet not only for utilitarian purposes but also for leisure and recreation. Based on the theory of flow, they consider playfulness as an intrinsic belief or motive, which is shaped by the individual's experience with the environment. A new intrinsic motivation factor-Perceived Playfulness, is introduced into the original TAM. Moon and Kim concluded that it is important for developers to include intrinsic and extrinsic motivational factors in user interface design, thus helping to improve user acceptance. Chen et al. (2002) supported this claim and found playfulness to be an important factor motivating users to use a virtual store. We adopt Moon and Kim's (2001) definition of Perceived Playfulness:

"The extent to which the individual perceives that his or her attention is focused on the interaction with the World-Wide-Web; is curious during the interaction; and finds the interaction intrinsically enjoyable or interesting" 
Several researchers have studied intrinsic motivator in the context of mobile internet services (Nysveen et al. 2005; Fang et al. 2006). In their study of four mobile services, Nysveen et al. (2005) found enjoyment plays an important role in determining user acceptance of these services. Fang et al. (2006) categorized mobile tasks that can be performed on handheld devices into three broad types: general task, transactional task and gaming task. They found Perceived Playfulness is significant when users are performing gaming tasks.

\section{Individual Differences and Autotelic Personality}

Individual differences refer to factors such as personality, situational, and demographic variables that influence user's beliefs about and use of information technology. In the context of flow, Webster and Martocchio (1992) studied microcomputer playfulness and suggest microcomputer playfulness act as an individual' tendency to interact spontaneously, inventively and imaginatively with microcomputers. It is a situation specific individual characteristic, which represents a type of cognitive playfulness. Moon and Kim (2001) considered Perceived Playfulness as an intrinsic belief or motive, which is formed by an individual's subjective experience with IS/IT. Hence, identifying those individual characteristics that lead to Perceived Playfulness may provide insight into this (stable) individual belief construct.

This study also explores whether these individual differences are likely to be the dimensions of Autotelic Personality. It draws upon previous research on flow as Perceived Playfulness is fundamentally based on flow. Prior work related to the state of flow with information technologies has highlighted four key factors that influence individuals to experience flow - namely:

- personal innovativeness (Aggarwal and Karahanna, 2000; Finneran and Zhang, 2005),

- $\quad$ self efficacy (Ghani et al., 1991; Hoffman and Novak, 1996; Novak et al., 2000; Lim, 2001; Koufaris, 2002),

- control (Ghani et al., 1991; Trevino and Webster, 1992; Webster et al., 1993; Ghani and Despande, 1994; Webster and Ho, 1997; Chen 2000; Koufaris, 2002; Chung and Tan, 2004),

- $\quad$ focused attention (Trevino and Webster, 1992; Webster et al., 1993; Hoffman and Novak, 1996; Novak et al., 2000; Koufaris, 2002; Chung and Tan, 2004).

The information systems (IS) and marketing literature on intrinsic motivators was drawn to identify these underlying dimensions. These dimensions were mainly ones found to be important to users experiencing playfulness, enjoyment, flow and engagement in the literature. These are described below.

\section{Personal Innovativeness}

Flow experience usually occurs in structured activities such as games, ritual events, sports, artistic performances, etc. (Csikszentmihalyi 1988). It does not normally occur in everyday life because challenges and skills are rarely balanced. However, even if skills and challenges are balanced, it does not guarantee a flow experience occurring. This is because activities only provide the challenges; it is still up to the individual to recognize the challenge, provide the skills, and extract enjoyment from the activity. Therefore, challenge is more related to the perceived complexities provoked by the activity rather than the individual per se. As Csikszentmihalyi (1988) stated; the complexity of a flow activity is limited by the degree of challenge it can provide, and by the willingness and "creativity" of the person to create challenges in an activity. Because of this reason, Personal Innovativeness introduced by Agarwal and Prasad (1998) is deemed important in the context of our study. Personal Innovativeness in the domain of information technology is conceptualized as an individual trait reflecting a willingness to try out any new technology. Furthermore, Agarwal and Karahanna (2000) provide empirical support of its influence on cognitive absorption, which is a construct similar to 
flow. In this regard, Pagani (2004) suggests that individual innovativeness can be seen as a willingness to adopt $3 \mathrm{G}$ multi-media services.

\section{Self Efficacy}

Self Efficacy is similar to Skill which has been well studied in research on flow (Koufaris, 2002; Ghani et al. 1991; Hoffman and Novak, 1996; Novak et al. 2000). Recall that the most important condition for a flow state to occur is when the challenges of a situation match the skills of the participant. Prior research has drawn distinction between general self-efficacy and computer selfefficacy (Compeau and Higgns, 1995). While the former being an overall judgement of an individual on efficacy across multiple computer application domains, the latter represents the judgement on specific task in the domain of general computing. Agarwal et al. (2000) pointed out that there is significant support for a relationship between self-efficacy and individual beliefs about IT. Their result suggests that software specific self-efficacy will have a stronger effect than the initial general self-efficacy due to the "carryover" effect, i.e. the accumulated application specific self-efficacy will eventually displace the effects of initial belief with the passage of time. Because of this reason, Computer Self Efficacy has been preferred over Skill as the latter may convey the meaning of general competency on everyday tasks.

\section{Control and Focused Attention}

Hoffman and Novak (1996) developed a theoretical model of flow within the hypermedia context. In this model, Challenges, Skills and Focused Attention were modelled as the primary antecedents of flow. Other secondary antecedents (Interactivity and Telepresence) were also added in accordance to the literature of hypermedia. The consequence of flow leads to increased learning, perceived control, exploratory behavior and positive experience. However, their earlier work was exploratory in nature therefore all the hypothesized relationships were not empirically tested. Novak et al. (2000) later revised the original model and added Control as a primary antecedent of flow. The revised model was then tested and results showed all these four antecedents exert positive and significant impact on Flow. A somewhat interesting finding is that they modeled Control and Skill together as a higherorder construct (i.e. Skill/Control). However, a distinction should be made between these two Control capturing an individual's perception that $\mathrm{s} /$ he exercises control over the interaction with environment (Webster et al.. 1993), whereas Self Efficacy (Skill) is the judgement on specific task in a specific domain prior to that interaction. Chung and Tan (2004) in their study also proposed Focused Attention and Control as two individual cognitive aspects that lead to Perceived Playfulness. From the review of the relevant literature, the following research question is developed:

Does Autotelic Personality (constituted by Personal Innovativeness, Self Efficacy, Control, and Focused Attention) influence Perceived Playfulness in the context of mobile information and entertainment services?

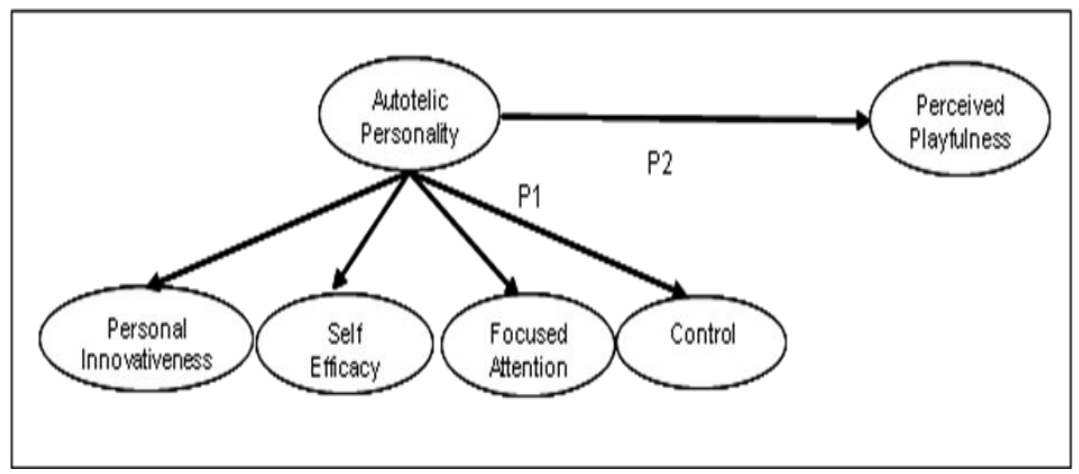

Figure 1: Research Model 
Figure 1 presents the research model. From the flow literature and the discussion above, we contend that (i) Autotelic Personality is a second-order reflective construct consisting of the following individual differences - Personal Innovativeness; Self Efficacy; Control; and Focused Attention, and (ii) that these characteristics are its first-order reflective indicators that individually and collectively influence the Perceived Playfulness experienced by the user.

As depicted in Figure 1, Autotelic Personality is portrayed as a multidimensional construct. It is considered a reflective construct for several reasons (Petter, Straub and Rai, 2007): (i) its indicators manifest the higher-order construct and as such the direction of causality is from the construct to the reflective indicators (see Figure 1); and (ii) its measures are interchangeable and have a common theme (see Appendix for the questionnaire).

The study therefore proposes that:

P1: Autotelic Personality is a second-order reflective construct consisting of Personal Innovativeness, Self efficacy, Control and Focused Attention,

P2: Autotelic Personality is positively related to Perceived Playfulness.

\section{RESEARCH METHODOLOGY}

\section{Sampling}

The sample consisted of students who attended information system and business lectures at a New Zealand university. Students from six classes were invited to complete the questionnaire (see Appendix). Students are appropriate target sample because they are likely to be literate and familiar with mobile internet, and are likely to have experience using mobile internet on a regular basis. Familiarity with using mobile internet services permit attitudes and beliefs to be measured based on direct behavioural experience (Davis, 1993).

A total of 186 questionnaires were returned. Incomplete questionnaires were discarded, leaving 149 usable samples. Most of these were from respondents who claimed not to have used MIES at all. No significant differences were found to exist between the group who claimed not to have used MIES and the group who did. Of those who did 94 were males and 55 were females aged mainly between $21-30$ years $(60.4 \%)$ and 20 years or less $(30 \%)$. Most have an undergraduate degree $(72.5 \%)$ and vary considerably in terms of years of computer experience - with $32 \% 8$ or more years experience, 23\% 6-7 years, 22\% 4-5 years and 15\% 2-3 years. On average, most of the respondents used MIES for no more than an hour a day $(63 \%)$.

In terms of phone categories, about $60 \%$ of all the respondents specified they have WAP-enabled mobile phone or General Packet Radio Service (GPRS) phone. Respondents holding a 3G mobile phone came second in the list, with a significant proportion of $12 \%$ among the respondents. Users of the Code Division Multiple Access (CDMA) mobile phone are relatively few, only $7 \%$ compared to other phone categories. At the same time, $21 \%$ of all the respondents are not sure about the phones they are using. When asked whether their phone provides a feature with which to access MIES services, $83 \%$ of the respondents answered "Yes" to this question. This indicates the wide availability of mobile internet capable phones in the New Zealand market.

MMS services were the most popular among the respondents with a total of $38 \%$ indicating using this MIES most recently. SMS-based services (i.e. ringtones, subscription-based information alerts and sending/receiving text messages) were the next most recently used MIES. The numbers of respondents using mobile email, information searching and mobile downloading most recently were $9 \%, 10 \%$ and $17 \%$ respectively. 


\section{Measures}

In terms of measurement, all items were constructed as agree-disagree statements on a seven-point Likert scale, which is consistent with the scales applied in prior research. Since the variables of interest have been previously validated under different contexts, mirroring the same items in a new context is straightforward. To ensure measurement reliability, items validated in previous research have been used (see Table 1). The measures for Personal Innovativeness, Self Efficacy, Control, Focused Attention and Perceived Playfulness were taken from previous IS research and were modified to suit the MIES context. Adopting the same measures as others instead of creating new measures enhances the comparability of the paper with others, specifically when existing measures already become a field standard (Churchill, 1999).

\begin{tabular}{|l|l|}
\hline Variable & Source \\
\hline Personal Innovativeness & Agarwarl and Prasad (1998) \\
\hline Self Efficacy & Hung et al. (2003) \\
\hline Control & Agarwal and Karahanna (2000) \\
\hline Focused Attention & Webster et al. (1993) \\
\hline Perceived Playfulness & Moon and Kim (2001) \\
\hline
\end{tabular}

Table 1: Measurements items

\section{DATA ANALYSIS AND RESULTS}

The data analysis technique employed in this study is Partial Least Squares (PLS). PLS is a recent technique that generalizes and combines features from principal component analysis and multiple regressions (Thompson et al. 1995). The PLS approach provides a means for directly estimating latent variable component scores. It is a technique comprised of measurement and structural models (Gefen et al. 2000). The aim of testing the measurement model is to specify how the latent variables are measured in terms of the observed variables, and how these are used to describe the measurement properties (validity and reliability) of the observed variables. The structural model investigates the strength and direction of the relationships among theoretical latent variables. Autotelic Personality as a second-order factor can be approximated using various procedures. One of the easiest to implement is the approach of repeated indicators known as the hierarchical component model suggested by Lohmöller (1989, pp. 130-133). In essence, a second-order factor is directly measured by observed variables for all the first-order factors. This procedure works best with equal numbers of indicators for each construct.

\section{Measurement Validation}

To measure internal consistency of a given block of indicators, internal composite reliability (ICR) scores were obtained through PLS-GRAPH to assess the reliabilities of each latent variable. Where the internal consistency of any latent variable exceeds 0.70 , this indicates tolerable reliability (Fornell and Larcker, 1981). As shown in Table 2, all latent variables in our model have internal consistencies greater than 0.7, indicating all constructs have high reliabilities. In addition, the average variance extracted (AVE) of each latent variable in our model are more than 0.50 (Table 2), guaranteeing a more valid variance explained than error in its measurement (Fornell and Larcher 1981).

Two validities were captured in the measurement model: convergent validity and discriminant validity. Essentially, they estimate how well the measurement items relate to the constructs. PLS performs confirmatory factor analysis to establish factorial validity regarding these two validities (Gefen and Straub, 2005). To test convergent validity of the measures associated with each construct, 
the loadings and cross loadings of each indicator on the latent variables must also be examined. Convergent validity is shown when the $t$-values of these loadings are above 1.96 (Gefen and Straub, 2005). The results (Table 3) indicate almost all measurement items exhibit very high convergent validity on their measured latent variables.

\begin{tabular}{|l|l|l|}
\hline Latent variables & ICR & AVE \\
\hline Personal Innovativeness & 0.896 & 0.683 \\
Self Efficacy & 0.953 & 0.870 \\
Control & 0.864 & 0.679 \\
Focused Attention & 0.751 & 0.520 \\
Perceived Playfulness & 0.866 & 0.576 \\
\hline
\end{tabular}

Table 2: Measurements items

However, it has been noticed that the first measure of Focused Attention (FoA1) and the first as well as the second measure of Perceived Playfulness (PP1 and PP2) exhibit very low loadings.

The way to establish discriminant validity is to examine the square root of the AVE of each construct to the correlations of this construct to all other constructs.

\begin{tabular}{|l|c|c|c|c|c|}
\hline & $\begin{array}{c}\text { Personal } \\
\text { Innovativeness }\end{array}$ & $\begin{array}{c}\text { Self } \\
\text { Efficacy }\end{array}$ & Control & $\begin{array}{c}\text { Focused } \\
\text { Attention }\end{array}$ & $\begin{array}{c}\text { Perceived } \\
\text { Playfulness }\end{array}$ \\
\hline Personal Innovativeness (PI1) & $\mathbf{0 . 7 7 4}$ & 0.257 & 0.331 & 0.190 & 0.177 \\
\hline Personal Innovativeness (PI2) & $\mathbf{0 . 8 6 9}$ & 0.410 & 0.417 & 0.261 & 0.438 \\
\hline Personal Innovativeness (PI3) & $\mathbf{0 . 8 1 6}$ & 0.492 & 0.412 & 0.104 & 0.443 \\
\hline Personal Innovativeness (PI4) & $\mathbf{0 . 8 2 6}$ & 0.372 & 0.357 & 0.213 & 0.364 \\
\hline Self Efficacy (SE1) & 0.410 & $\mathbf{0 . 8 8 0}$ & 0.443 & 0.041 & 0.468 \\
\hline Self Efficacy (SE2) & 0.408 & $\mathbf{0 . 8 7 7}$ & 0.443 & 0.012 & 0.477 \\
\hline Self Efficacy (SE3) & 0.475 & $\mathbf{0 . 9 5 9}$ & 0.470 & 0.045 & 0.488 \\
\hline Control (Ctrl1) & 0.401 & 0.430 & $\mathbf{0 . 8 4 6}$ & 0.304 & 0.459 \\
\hline Control (Ctrl2) & 0.281 & 0.344 & $\mathbf{0 . 7 6 9}$ & 0.256 & 0.329 \\
\hline Control (Ctrl3) & 0.442 & 0.415 & $\mathbf{0 . 8 1 8}$ & 0.369 & 0.532 \\
\hline Focused Attention (FoA1) & -0.021 & 0.017 & 0.123 & $\mathbf{0 . 5 4 6}$ & 0.025 \\
\hline Focused Attention (FoA2) & 0.067 & -0.058 & 0.168 & $\mathbf{0 . 6 9 8}$ & 0.088 \\
\hline Focused Attention (FoA3) & 0.225 & 0.052 & 0.379 & $\mathbf{0 . 8 6 6}$ & 0.281 \\
\hline Perceived Playfulness (PP1) & 0.152 & 0.076 & 0.226 & 0.300 & $\mathbf{0 . 4 3 4}$ \\
\hline Perceived Playfulness (PP2) & 0.107 & -0.063 & 0.093 & 0.218 & $\mathbf{0 . 1 0 5}$ \\
\hline Perceived Playfulness (PP3) & 0.432 & 0.357 & 0.453 & 0.290 & $\mathbf{0 . 7 7 9}$ \\
\hline Perceived Playfulness (PP4) & 0.316 & 0.418 & 0.404 & 0.278 & $\mathbf{0 . 7 7 5}$ \\
\hline Perceived Playfulness (PP5) & 0.291 & 0.483 & 0.404 & 0.208 & $\mathbf{0 . 7 6 8}$ \\
\hline Perceived Playfulness (PP6) & 0.379 & 0.488 & 0.498 & 0.230 & $\mathbf{0 . 8 4 6}$ \\
\hline
\end{tabular}

Table 3: Loading and Cross Loadings

In the PLS-GRAPH, the AVEs were obtained by performing a bootstrap re-sampling. Fornell and Larcker (1981) suggest that the square root of AVE should be greater than the corresponding correlations among the latent variables. The results shown in Table 4 demonstrate all latent variables 
exhibit high discriminant validities. The diagonal cells in the correlation matrix shown in Table 4 are the square root value of AVE for each latent variable.

\begin{tabular}{|l|c|c|c|c|c|}
\hline & $\begin{array}{c}\text { Personal } \\
\text { Innovativeness }\end{array}$ & $\begin{array}{c}\text { Self } \\
\text { Efficacy }\end{array}$ & Control & $\begin{array}{c}\text { Focused } \\
\text { Attention }\end{array}$ & $\begin{array}{c}\text { Perceived } \\
\text { Playfulness }\end{array}$ \\
\hline Personal Innovativeness & $\mathbf{0 . 8 2 4}$ & & & & \\
\hline Self Efficacy & 0.496 & $\mathbf{0 . 9 3 4}$ & & & \\
\hline Control & 0.468 & 0.498 & $\mathbf{0 . 8 2 2}$ & & \\
\hline Focused Attention & 0.287 & 0.074 & 0.412 & $\mathbf{0 . 8 0 8}$ & \\
\hline Perceived Playfulness & 0.486 & 0.534 & 0.557 & 0.316 & $\mathbf{0 . 7 3 9}$ \\
\hline
\end{tabular}

Table 4: Correlation Matrix and the Square Root of AVE

The initial test of the measurement model using confirmatory factor analysis indicated that some construct revisions were needed. The loadings and cross-loadings of indicators FoA1 and PP2 in Table 3 showed relatively low correlations on the latent constructs they were meant to describe. Essentially this result presents a need to re-specify the instruments. The approach described in Churchill (1979) is to purify the measures. Items that do not share equally in the common core were eliminated. As suggested by Straub et al. (2004), this approach can be applied to PCA, PLS and covariance-based SEM. As a result, FoA1, PP1 and PP2 were eliminated in the in the subsequent analysis.

\section{THE STRUCTURAL MODEL}

Figure 2 presents the results of the structural model. The structural model has an $\mathrm{R}^{2}$ of 0.439 thereby accounting for nearly $44 \%$ of the variances in the model.

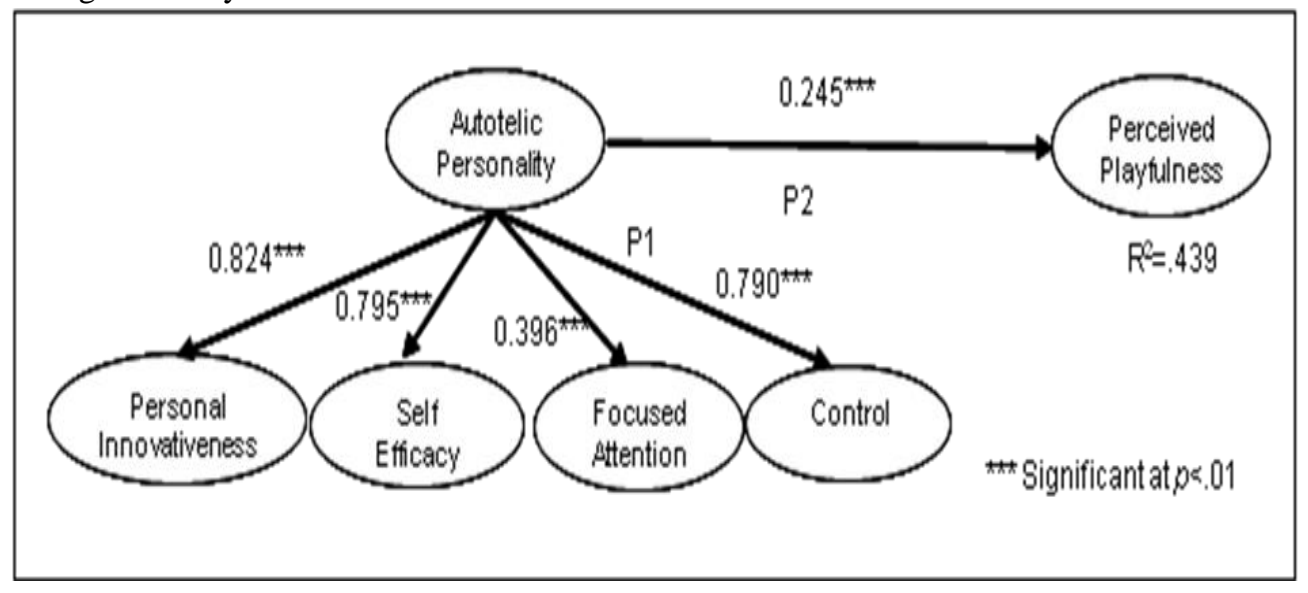

Figure 2: The Structural Model

As mentioned earlier, Autotelic Personality is a second-order reflective construct represented by the four first-order factors and their own indicators. When testing second-order constructs, the percentage of the paths should be at 0.70 or above to establish the convergent validities of the first-order factors (Chin, 1998). The steps outlined by Pavlou and El Sawy (2005) were employed to test the existence of a second order factor. Firstly, the correlations between the first order factors and the second order factor were tested. As shown in Figure 2, the correlations between Personal Innovativeness, Self 
Efficacy, Control and Autotelic Personality are highly correlated because the 0.70 threshold is met. Since a reflective model would assume the first and second-order constructs are extremely highly correlated, a formative model seems less likely for Autotelic Personality. The low loading from Autotelic Personality on Focused Attention (after measurement revision) casts doubt on its role in reflecting Autotelic Personality.

The item loadings and loadings of the first order factors on Autotelic Personality are shown in Table 5. Item loadings with a $t$-value above 2.0 are considered significant. All items have large and significant loadings on their corresponding factors indicating evidence of good construct validities (Doll et al, 1994). The $R$-square for each factor indicates that all first order factors, except for Focused Attention (i.e. Personal Innovativeness, Self Efficacy and Control) are reliably explained by Autotelic Personality. These results partially support the first proposition P1.

\begin{tabular}{|c|c|c|c|c|c|}
\hline \multicolumn{3}{|c|}{$\begin{array}{c}\text { Observed Variables (PI, SE, Ctrl \& } \\
\text { FoA) }\end{array}$} & \multicolumn{3}{|c|}{ Latent Variables (Autotelic Personality) } \\
\hline Item & Item loading & $\begin{array}{l}\text { - } \\
\text { statistics }\end{array}$ & Factor & $\begin{array}{l}\text { Factor } \\
\text { Loadings }\end{array}$ & $\begin{array}{l}\text { R-Square } \\
\text { (Reliability) }\end{array}$ \\
\hline PerInnov1 & 0.7744 & 16.3283 & \multirow{4}{*}{$\begin{array}{l}\text { Personal } \\
\text { Innovativeness }\end{array}$} & \multirow[t]{4}{*}{0.820} & \multirow[t]{4}{*}{0.672} \\
\hline PerInnov2 & 0.8685 & 39.6413 & & & \\
\hline PerInnov3 & 0.8166 & 28.0138 & & & \\
\hline PerInnov4 & 0.8469 & 22.1562 & & & \\
\hline SelfEffy1 & 0.9354 & 72.7521 & \multirow[t]{3}{*}{ Self Efficacy } & \multirow[t]{3}{*}{0.797} & \multirow[t]{3}{*}{0.636} \\
\hline SelfEffy 2 & 0.9073 & 27.8973 & & & \\
\hline SelfEffy3 & 0.9603 & 91.6832 & & & \\
\hline Control1 & 0.8370 & 31.1400 & \multirow[t]{3}{*}{ Control } & \multirow[t]{3}{*}{0.792} & \multirow[t]{3}{*}{0.627} \\
\hline Control2 & 0.7903 & 22.3422 & & & \\
\hline Control3 & 0.8157 & 20.3454 & & & \\
\hline FocAttn2 & 0.6491 & 1.9574 & \multirow{2}{*}{$\begin{array}{l}\text { Focused } \\
\text { Attention }\end{array}$} & \multirow[t]{2}{*}{0.398} & \multirow[t]{2}{*}{0.158} \\
\hline FocAttn3 & 0.9623 & 3.7664 & & & \\
\hline
\end{tabular}

Table 5: Validities and t-values for Autotelic Personality (4 first order factors, 1 second order factor)

Next, a mediation test was performed to see if the second order construct fully mediates the relationship between the first order factors and the theorized dependent variable (Chin, 1998). Fig 33(a) shows the impact of each first order factor on Perceived Playfulness individually. Personal Innovativeness, Self Efficacy, Control and Focused Attention all show significant effects on Perceived Playfulness at the 0.01 level.

In Fig 3-3(b), Autotelic Personality is used as a more parsimonious second order factor and it shows significant correlation with all first order factors. As a surrogate of its first order factors, Autotelic Personality strongly influences Perceived Playfulness and is highly significant $(\beta=0.647, t=11.2900)$. This aggregate measure is the only significant predictor of Perceived Playfulness when all first order factors are controlled for. This is indicated by the weak correlation (dotted line) between first order factors and Perceived Playfulness in the presence of Autotelic Personality. Based on this analysis, there is support for the second proposition P2. 


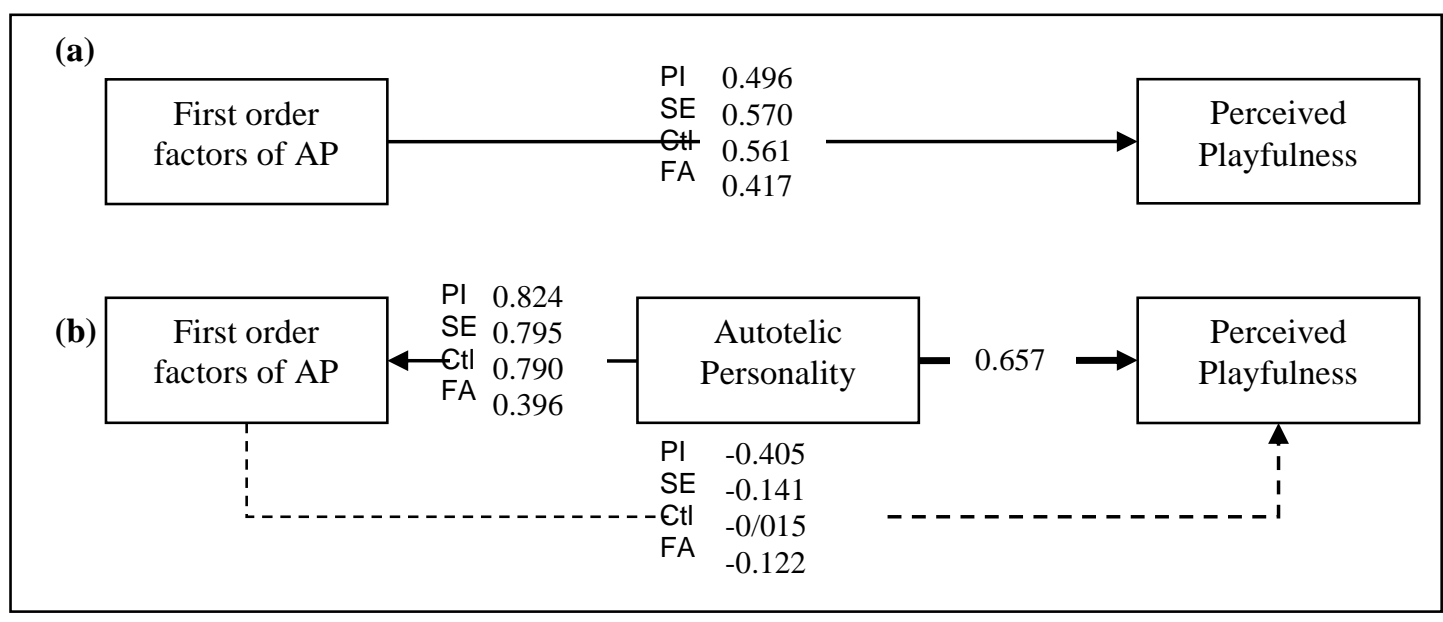

Figure 3-3 The mediation effect of Autotelic Personality (PI: Personal Innovativeness SE: Self Efficacy Ctl: Control FA: Focused Attention)

\section{DISCUSSION}

Chin and Gopal (1995) suggest the relative importance of the reflective model is established by contrasting the loadings from the overall latent belief with each of the individual beliefs. Each belief represents a separate attitudinal dimension, which reflects an existing overall attitude. Our findings suggest all underlying factors (Personal Innovativeness, Self- Efficacy, Control and Focused Attention) significantly correlated with Autotelic Personality. The loading of Focused Attention indicates it is not an important underlying belief in reflecting Autotelic Personality compared to other factors. According to Buchanan et al. (2001), navigating the mobile internet via mobile phones can be a daunting experience given the constraints of small screen display and cumbersome input mechanisms. A common criticism of early WAP sites was that they involved too many selections and moves between menus and submenus, for the user to get to their desired contents. Therefore, user's Focused Attention is likely to be affected by the screen size of mobile phones (Buchanan et al. 2001; Sweeney and Crestani, 2006).

Our findings suggest all underlying factors (Personal Innovativeness, Self- Efficacy, Control and Focused Attention) significantly correlated with Autotelic Personality. On the other hand, only Personal Innovativeness, Self Efficacy and Control significantly determine Perceived Playfulness. High correlations were also identified between these three factors and Autotelic Personality. This is consistent with Asakawa's (2004) finds that autotelic students are those who feel more in control of the situation and positive about challenges as compared to their non-autotelic counterparts. Acknowledging that an autotelic person perceives challenges differently from a non-autotelic person, this study integrated Personal Innovativeness as one of the underlying dimension of Autotelic Personality (Agarwal and Karahanna, 2000). The higher loading of Autotelic Personality on Personal Innovativeness and Control indicates both constructs are important dimensions of Autotelic Personality. This study also provides empirical evidence that Self Efficacy is a significant dimension of Autotelic Personality in the context of MIES. 
Asakawa (2004) discovered autotelic students have more balanced level of perceived challenges and perceived skills suggesting the latter is an important dimension of Autotelic Personality. In this study, we provide empirical evidence that Self Efficacy, which is similar to skill, is a significant dimension of Autotelic Personality in the context of MIES. More importantly, Autotelic Personality is reflected in only one combination of these measures: Personal Innovativeness, Self Efficacy and Control and is positively related to Perceived Playfulness. This study thus empirically supports the existence of this important construct and the predisposition of its core dimensions to lead to the occurrence of Perceived Playfulness in the context of MIES. It is suggested that these individual differences within Autotelic Personality stimulate users to engage in MIES activities for the Perceived Playfulness that accompanies these activities.

While users' personalities remain a complex phenomenon, this study shows that an understanding of their Autotelic Personality sets a new direction for market segmentation. The marketing literature suggests that there are two main reasons to segment a market - to explore new product opportunities and to develop improved advertising messages by better understanding one's customers. From the findings, these users are genuinely high on personal innovativeness - regarding themselves among their peers to usually be the first to try out and experiment with new technologies; are confident and independent users of mobile-based application; and who place importance on feeling in control when using MIES. Autotelic users will recognise new challenges (e.g. new features and functionalities) that confront them by providing the skills in order to extract enjoyment out of the activity. Providers are advised to consider identifying this segment, formulating effective marketing strategies to better target this user group. As commonly agreed by many other researchers in mobile commerce, the youth segment is likely to be the segment with the greatest potential, as they have more opportunities to interact with new technologies, have better education and are more innovative.

This study was however limited in a number of ways. First, this study is cross-sectional in nature and uses a convenient sample. Thus, some caution must be exercised when generalizing the findings. Second, this study did not examine the adoption of MIES. Therefore, the importance of Perceived Playfulness in the context of using MIES cannot be established. Future research on this can shed new light on user adoption of MIES. Third, common method bias may be introduced as the questionnaire employed may affect the scores or measures that are being gathered. Attempts to minimize the impact of common methods bias were implemented by using procedural remedies, including guaranteeing respondent anonymity and assuring respondents that there were no correct or incorrect answers (Podsakoff, MacKensie, Lee, \& Podsakoff, 2003).

In a study using flow theory, Ghani and Deshpande (1994) established that certain cognitive behaviour was related to different task characteristics. For example, perceived control was more important for individuals working on high uncertainty tasks. Similarly, respondents working on experientially directed tasks had a stronger tendency to experience Perceived Playfulness confirming that Flow was more apparent in experientially directed activities than goal-directed ones (Chung and Tan, 2004). Others have also found, among other variables, task characteristics and task variety influence students use of the Internet (Seyal and Rahman, 2003). We encourage further investigation into the moderating effect of task characteristics in MIES adoption.

\section{CONCLUSION}

This paper investigated those individual differences determining user's Perceived Playfulness in the context of mobile information and entertainment services. Based on the flow literature, this study also verified an important individual construct-Autotelic Personality and its significant influence on Perceived Playfulness. Our findings suggest individuals with Autotelic Personality are more likely to experience Perceived Playfulness in relation to these services. They also exhibit some characteristics 
in common, such as innovativeness and confidence about their ability to perform and feeling of control when using these services. More importantly, the validation of Autotelic Personality in the context of this study provides evidence for the existence of this higher order construct which is jointly reflected by its first-order beliefs (Personal Innovativeness, Self Efficacy and Control).

In summary, the important dimensions of Autotelic Personality are: Personal Innovativeness, SelfEfficay and Control. These dimensions are positively related to Perceived Playfulness. This study thus empirically found the existence of this important construct and the predisposition of its core dimensions that can lead to the occurrence of Perceived Playfulness in the context of MIES. Our findings suggest individuals with Autotelic Personality are more likely to experience Perceived Playfulness in relation to these services. In terms of practice, it is possible to use these dimensions to address the unique needs of different user groups. For example, it might be a possibility to categorize MIES users according to the importance of Personal Innovativeness, Self Efficacy and Control when designing marketing strategies for service offerings. As Hoffman and Novak (1996) suggest, this has crucial implications for market segmentation of the mobile marketplace.

\section{COPYRIGHT}

Copyright (C) Australian Computer Society Inc. General permission to republish, but not for profit, all or part of this material is granted, under the Creative Commons Australian AttributionNonCommercial-NoDerivs 2.5 Licence, provided that the copyright notice is given and that reference is made to the publication, to its date of issue, and to the fact that reprinting privileges were granted by permission of the Copyright holder.

\section{REFERENCE}

Agarwal, R., \& Karahanna, E. (2000). Time flies when you're having fun: Cognitive Absorption and Beliefs about Information Technology Usage. MIS Quarterly, 24, 665-694.

Agarwal, R., \& Prasad, J. (1998). A Conceptual and Operational Definition of Personal Innovativeness in the Domain of Information Technology. Information Systems Research, 9(2), 204-215.

Ahn, T., Ryu, S. \& Han, I. (2007). The impact of web quality and playfulness on user acceptance of online retailing. Information \& Management, 44(3), 263-275.

Asakawa, K. (2004). Flow experience AND autotelic personality In Japanese College students: How Do They experience challenges In Daily life?. Journal of Happiness studies, 5(2), 123-155.

Baldi, S., \& Thaung, H. P. P. (2002). The entertaining way to m-commerce: Japan's approach to the mobile internet - a model for Europe? Electronic Markets, (12)1, 6-13.

Bhatnagar, A., Misra, S., \& Rao, H. R. (2000). On Risk, Convenience and Internet Shopping Behavior. Communications of the ACM, 43(11), 98-105.

Buchanan G, Jones M., Thimbleby H., Farrant S. \& Pazzani M. (2001). Improving mobile Internet usability. Proceedings of the 10th International Conference on World Wide Web, Hong Kong, May 2001, pp 673-680. ACM Press.

Chen, L.-D., Gillenson, M. \& Sherrell D. (2002). Enticing online consumers: An extended technology acceptance perspective. Information and Management 39, pp. 705-719.

Cheong, J.H. \& Park, M-C. (2005). Mobile internet acceptance in Korea. Internet Research, 15(2), 125-140. 
Chin, W. W. (1998). Issues and Opinion on Structural Equation Modeling. MIS Quarterly, 22(1), pp. vii - xvi.

Chin, W. W., \& Gopal, A. (1995). Adoption intention in GSS: Relative importance of beliefs. The Data Base for Advances in Information Systems, 26(2/3), 42-64.

Chung, J., \& Tan, F. B. (2004). Antecedents of Perceived Playfulness: An Exploratory Study on. User Acceptance of General Information-Searching Websites. Information \& Management, 41(7), 869-881.

Churchill, G. (1979). A paradigm for developing better measures of marketing constructs. Journal of Marketing Research, 16, 64-73.

Churchill, G. (1999). Marketing Research: Methodological Foundation. New York: The Dryden Press.

Compeau, D. R., and Higgins, C. A. (1995) Computer Self-Efficacy: Development of a Measure and Initial Test, MIS Quarterly, (19:2), 189-211.

Csikszentmihalyi, M. (1988). The Future of Flow. In Csikszentmihalyi, M., \& Csikszentmihalyi, I. S. (Eds.), Optimal Experience: Psychological Studies of Flow in Consciousness (pp.364-383). New York.

Davis, F. (1989). Perceived Usefulness, Perceived Ease of Use, and User acceptance of Information Technology. MIS Quarterly, 13, 318-339.

Davis, F. (1993). User acceptance of information technology: system characteristics, user perceptions and behavioural impacts. International Journal of Man-Machine Studies, 38, 475-487.

Doll, W.J., Xia, W., \& Torkzadeh, G. (1994). .A Confirmatory Factor Analysis of the End-User Computing Satisfaction Instrument. MIS Quarterly, 18, 453-461.

Fang, X. W., Chan, S., Brzezinski, J., \& Xu, S. (2006). Moderating Effects of Task Types on Wireless Technology Acceptance. Journal of Management Information Systems, 22(3), 123-157.

Finneran, C. M., \& Zhang, P. (2005). Flow in computer-mediated environments: Promises and challenges. Communications of the Association for Information Systems, 15, 82-101.

Fornell, C., \& Larcker, D. F. (1981) Evaluating Structural Equation Models with Unobservable Variables and Measurement Error. Journal of Marketing Research, 18, 39-50.

Garcia-Macias, J. A., Rousseau, F., Berger-Sabbatel, G., Toumi, L., \& Duda, A. (2003). Quality of Service and Mobility for the Wireless Internet. Wireless Networks, 9, 341-352.

Gefen, D., \& Straub, D. (2005). A Practical Guide to Factorial Validity Using PLS-Graph: Tutorial and Annotated Example. Communications of the Association for Information Systems, 16(5), 91-109.

Gefen, D., Straub, D., \& Boudreau, M.C. (2000). Structural Equation Modeling and Regression: Guidelines for Research Practice. Communications of the Association for Information Systems, 4(7), 1-80.

Ghani, J. (1991). Flow in human computer interactions: test of a model. In: Carey, J. (Ed.), Human Factors in Information Systems: Emerging Theoretical Bases. New Jersey: Ablex Publishing Corp.

Ghani, J., \& Deshpande, S. (1994). Task Characteristics and the Experience of Optimal Flow in Human-Computer Interaction. The Journal of Psychology, 128, 381-391.

Ghani, J., Supnick, R., \& Rooney, P. (1991). The Experience of Flow in Computer-Mediated and in Face-to-Face Group. In Degross, J., Benbasat, I., DeSanctics, G., \& Beath, C. (Eds.), Proceedings of the Twelfth International Conference on Information Systems (pp. 229-238). New York. 
Hoffman, D. L., \& Novak T. P. (1996). Marketing in Hypermedia Computer-Mediated Environments: Conceptual Foundations. Journal of Marketing, 60, 50-68.

Hung, S. Y., Ku, C. Y., \& Chang, C. M. (2003). Critical factors of WAP services adoption: An empirical study. Electronic Commerce Research and Applications, 2, 42-60.

Koufaris, M. (2002). Applying the technology acceptance model and flow theory to online consumer behavior. Information Systems Research, 13(2), 205-23.

Lee, M.K.O., Cheung, C.M.K. \& Chen, Z. (2005). Acceptance of Internet-based learning medium: The role of extrinsic and intrinsic motivation. Information \& Management, 42(8), 1095-1104.

Lim, N. (2001) Customers' Beliefs Behind Business- to- Consumer Electronic Commerce. Australasian Journal of Information Systems, 9(1), 70-78.

Lin, C.S., Wu, S. \& Tsai, R.J. (2005). Integrating perceived playfulness into expectation-confirmation model for web portal context. Information \& Management, 42(5), 683-693.

Lohmoller, J. B. (1989). The PLS Program System: Latent Variables Path Analysis with Partial Least Squares Estimation. Multivariate Behavioral Research (23), pp. 125-127.

Moon, J. W., \& Kim, Y. G. (2001). Extending the TAM for a World-Wide-Web context. Information \& Management, (38)4, 217-230.

Nakamura, J., \& Csikszentmihalyi, M. (2002). The concept of flow. In C.R. Snyder \& S.J. Lopez (Eds.), Handbook of positive psychology (pp. 89-105). New York: Oxford University Press.

Novak, T. P., Hoffman, D. L., \& Yung, Y.-F. (2000). Measuring the Customer Experience in Online Environments: A Structural Modeling Approach. Marketing Science, 19(1), 22-42.

Nysveen, H., Pedersen, P. E., \& Thorbjørnsen, H. (2005). Intentions to Use Mobile Services: Antecedents and Cross-Service Comparisons. Journal of the Academy of Marketing Science, 33(3), 330-346.

Pagani, M. (2004).Determinants of Adoption of Third Generation Mobile Multimedia Services. Journal of Interactive Marketing, 18(3), 46-59.

Pavlou, P. A., \& El Sawy, O. A. (2005). From IT competence to competitive advantage in turbulent environments: A dynamic capabilities model (Working paper). University of California

at Riverside.

Pedersen, P.E. (2005). Adoption of mobile internet services: An exploratory study of mobile commerce early adopters. Journal of Organizational Computing and Electronic Commerce, 15(2), 2003-222.

Petter, S., Straub, D. \& Rai, A. (2007) Specifying Formative Constructs in Information Systems Research. MIS Quarterly, 31(4), 623-656.

Podsakoff, P. M., MacKensie, S. B., Lee, J-Y., \& Podsakoff, N. P. (2003). Common method biases in behavioral research: A critical review of the literature and recommended remedies. Journal of Applied Psychology, 88(5), 879-903.

Seyal, A.; Rahman, M. (2003) Student Use of the Internet: an extension of TAM in technical and vocational institutions in Brunei Darussalam. Australasian Journal of Information Systems, 10(2), 91-104.

Shim, J. P., \& Shim, J. (2003). M-commerce around the World: Mobile Services and Applications in Japan, Korea, Hong Kong, Finland, and the United States. Decision Line, September/October issue.

Sweeney, S., Crestani, F. (2006), Effective search results summary size and device screen size: Is there a relationship? Information Processing \& Management, 42(4), 1056-1074 
Thompson, R., Barclay, D., \& Higgins, C. (1995). The partial least squares approach to causal modeling: personal computer adoption and use as an illustration. Technology studies: special issue on research methodology, 2(2), 284-324.

Trevino, L. K., \& Webster, J. (1992). Flow in Computer-Mediated Communication. Communication Research, 19(5), 539-573.

Van de Kar, E. A. M., Maitland, C., Wehn de Montalvo, U., \& Bouwman, H. (2003). Design guidelines for Mobile Information and Entertainment Services; Based on the Radio538 ringtunes i-mode service case study. In Sadeh, Norman (Ed.); Proceedings of the Fifth International Conference on Electronic Commerce; 414-422.

Webster, J., \& Martocchio, J. (1992). Microcomputer playfulness: Development of a measure with workplace implications. MIS Quarterly, June, 201-226.

Webster, J., Trevino, L. K., \& Ryan, L. (1993). The dimensionality and correlates of flow in humancomputer interactions. Computers in Human Behavior, 9(2), 411-426.

Wu, J-H. \& Wang, S-C. (2005). What drives mobile commerce? An empirical evaluation of the revised technology acceptance model. Information \& Management, 42(5), 719-729. 


\section{Appendix: Questionnaire}

Research on Users' Experience with Mobile Information and Entertainment Services

\section{Purpose}

The objective of this questionnaire is to investigate users' experience with mobile information and entertainment services via mobile phones (PDA and Pocket PC are not included). Participation will only take ten minutes and your response to this questionnaire will provide information for our study. All responses from the survey are anonymous and are kept strictly confidential.

Definition of Mobile Information and Entertainment Services (MIES)

Mobile information and entertainment services (MIES) may be defined as the delivery of information and entertainment from specially formatted content sources (such as e-mail, MMS, SMS-based services, screen graphics and ring tone downloading, new, weather reports, and internet sites etc) via the mobile telecommunication network to a mobile phone user.

1. Which of the following applies to your mobile phone? (Please circle the one applicable)

a) WAP-enabled mobile phone or GPRS capable phone

b) 3G Mobile phone

c) CDMA mobile phone

d) None of these or Not Sure

2. Does your mobile phone provide a feature (for example: WAP) that allows you to access mobile information and entertainment services on your phone?

$$
\text { Yes } \quad \text { No } \quad \text { (Please tick one only) }
$$

3. Which of the following mobile information and entertainment services did you use most recently? (Please circle one only)
a) Mobile E-mail
b) MMS (e.g. PXT)
c) Information services (news, entertainment, sports, lifestyle etc)
d) Download (music and tones, screen tattoos or java games etc)
e) None of these services

4. Have you ever used SMS-based services on your mobile phone? (Examples: request information of account balance, unused free minutes or sending/receiving text messages etc)

$$
\text { Yes } \square \quad \text { No } \square \quad \text { (Please tick one only) }
$$

If you have never used any of those services specified in Questions 3 and 4, you are NOT required to answer the following questions below. Please return the questionnaire back to instructor. Otherwise, please continue.

The following questions relate to the Mobile Information and Entertainment Service (MIES) you have selected in Question 3. However, if you selected "none of these services" in question 3, you can use SMS-based services as a mobile information and entertainment service to answer the following questions.

Please indicate your agreement with the next set of statements by circling the appropriate number:

\begin{tabular}{llll}
\hline Item & Rating scale & & \\
\cline { 2 - 3 } & Strongly & Neutral & Strongly \\
& Agree & Disagree \\
\hline
\end{tabular}

Personal Innovativeness 


\begin{tabular}{|c|c|c|c|c|c|c|c|}
\hline $\begin{array}{l}\text { Among my peers, I am usually the first to try out new } \\
\text { information technologies }\end{array}$ & 1 & 2 & 3 & 4 & 5 & 6 & 7 \\
\hline $\begin{array}{l}\text { If I heard about a new information technology, I would look } \\
\text { for ways to experiment with it }\end{array}$ & 1 & 2 & 3 & 4 & 5 & 6 & 7 \\
\hline In general, I hesitate to try out new information technologies & 1 & 2 & 3 & 4 & 5 & 6 & 7 \\
\hline I like to experiment with new information technologies & 1 & 2 & 3 & 4 & 5 & 6 & 7 \\
\hline Self Efficacy & & & & & & & \\
\hline I would feel comfortable using MIES on my own & 1 & 2 & 3 & 4 & 5 & 6 & 7 \\
\hline $\begin{array}{l}\text { I will be able to use MIES even if there was no one around to } \\
\text { help me }\end{array}$ & 1 & 2 & 3 & 4 & 5 & 6 & \\
\hline I would be able to use MIES reasonably well on my own & 1 & 2 & 3 & 4 & 5 & 6 & 7 \\
\hline \multicolumn{8}{|l|}{ Focused Attention } \\
\hline When using MIES, I thought about other things & 1 & 2 & 3 & 4 & 5 & 6 & 7 \\
\hline When using MIES, I was aware of distractions & 1 & 2 & 3 & 4 & 5 & 6 & 7 \\
\hline When using MIES, I was totally absorbed in what I was doing & 1 & 2 & 3 & 4 & 5 & 6 & 7 \\
\hline \multicolumn{8}{|l|}{ Control } \\
\hline When using MIES I feel in control & 1 & 2 & 3 & 4 & 5 & 6 & 7 \\
\hline I feel that I have no control over my interaction with MIES & 1 & 2 & 3 & 4 & 5 & 6 & 7 \\
\hline The MIES allow me to control my mobile phone interaction & 1 & 2 & 3 & 4 & 5 & 6 & 7 \\
\hline \multicolumn{8}{|l|}{ Perceived Playfulness } \\
\hline When interacting with MIES I did not realise time had elapsed & 1 & 2 & 3 & 4 & 5 & 6 & 7 \\
\hline $\begin{array}{l}\text { When interacting with MIES, I often forgot the task I was } \\
\text { doing }\end{array}$ & 1 & 2 & 3 & 4 & 5 & 6 & 7 \\
\hline Interacting with MIES lead to exploration & 1 & 2 & 3 & 4 & 5 & 6 & 7 \\
\hline When interacting with MIES I had fun & 1 & 2 & 3 & 4 & 5 & 6 & \\
\hline Interacting with MIES was enjoyable & 1 & 2 & 3 & 4 & 5 & 6 & \\
\hline Overall, I encountered a positive experience from using MIES & 1 & 2 & 3 & 4 & 5 & 6 & \\
\hline
\end{tabular}

Please provide information about your background for our study by answering the following questions. This survey is anonymous and confidentiality will be strictly adhered.

Please circle the one that is applicable to you:

\begin{tabular}{|c|c|}
\hline Gender & a) Male b) Female \\
\hline Age & a) 20 or less b) $21-30$ c) $31-40$ d) $41-50$ e) 51 or above \\
\hline Highest education & $\begin{array}{l}\text { a) Primary school b) Secondary school c) Undergraduate degree d) Postgraduate } \\
\text { degree }\end{array}$ \\
\hline Computer experience (years) & a) 1 or less b) $2-3$ c) $4-5$ d) 6-7 e) 8 or above \\
\hline $\begin{array}{l}\text { Average time of using MIES per } \\
\text { week }\end{array}$ & a) None b) 1 or less c) $2-4$ d) $5-7$ e) 8 or above \\
\hline $\begin{array}{l}\text { Average time of using MIES per } \\
\text { day }\end{array}$ & $\begin{array}{l}\text { a) Never/almost none b) less than } 1 / 2 \text { hour c) } 1 / 2 \sim 1 \text { hour d) } 1 \sim 2 \text { hrs e) } 2 \sim 3 \text { hours } \\
\text { f) more than } 3 \text { hours }\end{array}$ \\
\hline Ethnic origin & a) NZ European b)NZ Maori c) European d) Asian e) Indian f) Other \\
\hline
\end{tabular}

